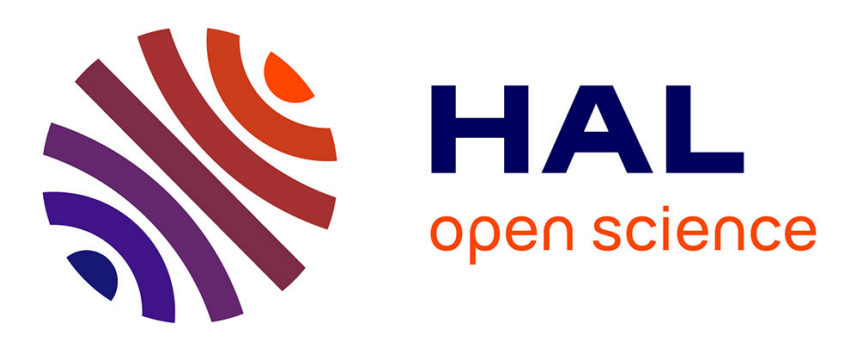

\title{
Improvement of the photoluminescence properties in a-SiNx films by introduction of hydrogen
}

\author{
M. Molinari, H. Rinnert, M. Vergnat
}

\section{To cite this version:}

M. Molinari, H. Rinnert, M. Vergnat. Improvement of the photoluminescence properties in aSiNx films by introduction of hydrogen. Applied Physics Letters, 2001, 79 (14), pp.2172-2174. 10.1063/1.1408905 . hal-02164218

\section{HAL Id: hal-02164218 \\ https://hal.science/hal-02164218}

Submitted on 24 Jun 2019

HAL is a multi-disciplinary open access archive for the deposit and dissemination of scientific research documents, whether they are published or not. The documents may come from teaching and research institutions in France or abroad, or from public or private research centers.
L'archive ouverte pluridisciplinaire HAL, est destinée au dépôt et à la diffusion de documents scientifiques de niveau recherche, publiés ou non, émanant des établissements d'enseignement et de recherche français ou étrangers, des laboratoires publics ou privés. 


\title{
Improvement of the photoluminescence properties in $a-\mathrm{SiN}_{x}$ films by introduction of hydrogen
}

\author{
M. Molinari, H. Rinnert, ${ }^{\text {a) }}$ and M. Vergnat \\ Laboratoire de Physique des Matériaux, (U.M.R. C.N.R.S. No 7556), Université Henri, Poincaré Nancy 1, \\ B.P. 239, 54506 Vandouvre-lès-Nancy Cedex, France
}

(Received 27 April 2001; accepted for publication 31 July 2001)

\begin{abstract}
Photoluminescence properties of amorphous hydrogenated silicon nitride thin films with various compositions are presented. The as-deposited samples prepared by evaporation of silicon under a flow of nitrogen and hydrogen ions exhibit visible photoluminescence at room temperature without any annealing treatment. The evolution of the photoluminescence properties with increasing nitrogen concentration in the films is correlated to structural investigations performed with Fourier-transform infrared spectroscopy and optical characterization obtained from transmission measurements in the ultraviolet-visible-near-infrared range. It is shown that the introduction of hydrogen is of prime importance to improve the photoluminescence intensity of the films. (C) 2001 American Institute of Physics. [DOI: 10.1063/1.1408905]
\end{abstract}

Since the observation of an intense visible light emission in porous $\mathrm{Si}$, a great number of studies have been performed on silicon and its alloys for their potential optoelectronic and display applications and in order to understand the physical mechanism involved in the photoluminescence (PL) phenomenon. Several models have been proposed to explain the light emission such as oxygen defects, ${ }^{1,2}$ siloxene species, ${ }^{3}$ amorphous $\mathrm{Si}$ (Ref. 4) or quantum confinement. ${ }^{5}$ Most of these models come from studies on Si-based materials containing oxygen like $a-\mathrm{SiO}_{x}$ films, ${ }^{6} \mathrm{Si}$ nanoclusters in $\mathrm{SiO}_{2},{ }^{7}$ $\mathrm{Si} / \mathrm{SiO}_{2}$ multilayers ${ }^{8}$ in which the role of oxygen cannot be neglected. There are very few studies of oxygen-free materials like pure $\mathrm{SiC}$ (Ref. 9) or $\mathrm{SiN}$ which could also give complementary information on the PL mechanisms. Hydrogenated amorphous silicon nitride $\left(a-\mathrm{SiN}_{x}: \mathrm{H}\right)$ films are generally prepared by chemical vapor deposition and exhibit either visible PL at low temperature ${ }^{10-12}$ or PL at room temperature but in the ultraviolet (UV) domain. ${ }^{13}$ The few other studies of $\mathrm{PL}$ in $a-\mathrm{SiN}_{x}: \mathrm{H}$ have shown visible $\mathrm{PL}$ at room temperature but after annealing treatments. ${ }^{14,15}$ The purpose of this letter is to show that it is possible to observe intense visible PL at room temperature in as-deposited films without any posttreatment and to clarify the role of hydrogen.

The $a-\mathrm{SiN}_{x}: \mathrm{H}$ thin films were prepared by an ion-beamassisted evaporation technique. Silicon was evaporated from an electron beam gun under the flow of nitrogen and hydrogen ions provided by an electron cyclotron resonance plasma source. Samples of different composition were prepared by varying the ratio of $\mathrm{N}_{2}$ and $\mathrm{H}_{2}$ in the gaseous mixture. The gaseous flow was regulated by maintaining the total pressure in the evaporation chamber at $2 \times 10^{-5}$ Torr. The deposition rate was equal to $1 \AA$ s. Films were deposited on silicon and fused silica substrates maintained at $100{ }^{\circ} \mathrm{C}$. Different nitrogen-hydrogen gaseous mixtures were used with a nitrogen percentage $p$. Chemical bonds were studied with

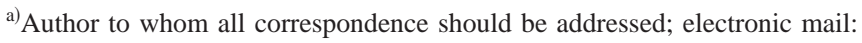
rinnert@1pm.u-nancy.fr
}

Fourier-transform infrared spectroscopy (FTIR). Spectra were performed with a Nicolet 460 Fourier-transform spectrometer with a resolution of $4 \mathrm{~cm}^{-1}$. The FTIR spectra were all background subtracted. The optical transmission measurements were performed in the range $190-3300 \mathrm{~nm}$ by a Varian Cary 5 ultraviolet-visible-near infrared (UV-Vis-NIR) spectrophotometer. PL measurements were carried out with a multichannel Jobin Yvon T64000 Raman spectrometer equipped with a 300 grooves $/ \mathrm{mm}$ grating. The detector was a charge coupled device camera cooled at $140 \mathrm{~K}$. The $488 \mathrm{~nm}$ excitation light source was emitted from a Spectra Physics argon laser.

The values of the optical gap $E_{g}$ are represented in Fig. 1. These values are derived from the Tauc relation ${ }^{16}$ using optical transmission experiments results. The Tauc gap of the sample prepared with little nitrogen $(p=8 \%)$ is equal to $1.96 \mathrm{eV}$. With increasing nitrogen concentration up to $p$ $=50 \%$, the gap slightly increases up to $2.16 \mathrm{eV}$. For higher nitrogen concentration $(p>50 \%), E_{g}$ decreases rapidly and is equal to $1.4 \mathrm{eV}$ for the unhydrogenated film.

Figure 2 shows the FTIR transmission spectrum of the sample prepared with $p=20 \%$. The vibration modes at 630 , 850,2150 , and $3350 \mathrm{~cm}^{-1}$ are attributed to the $\mathrm{Si}-\mathrm{H}$ wagging mode, the asymmetric $\mathrm{Si}-\mathrm{N}$ stretching mode, the $\mathrm{Si}-\mathrm{H}$

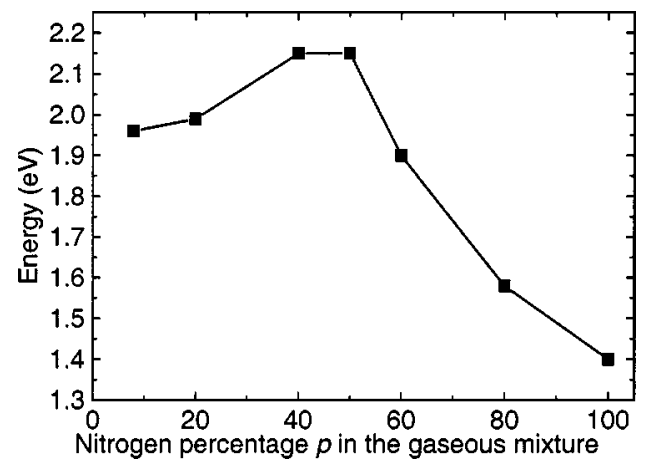

FIG. 1. Tauc gap of $a-\mathrm{SiN}_{x}: \mathrm{H}$ samples as a function of the nitrogen percentage $p$ in the gaseous mixture is shown. 


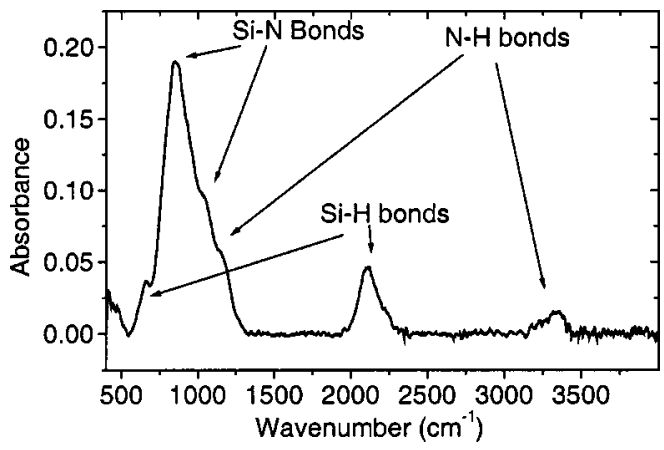

FIG. 2. Infrared absorption spectrum of the $a-\mathrm{SiN}_{x}: \mathrm{H}$ sample prepared with $p=20 \%$ is shown.

stretching mode and the $\mathrm{N}-\mathrm{H}$ stretching mode. ${ }^{17-19}$ The shoulders at 1020 and $1150 \mathrm{~cm}^{-1}$ are due to the $\mathrm{Si}-\mathrm{N}$ bond with an hydrogen atom back bonded to the silicon atom and to the $\mathrm{N}-\mathrm{H}$ rocking vibration, respectively. ${ }^{20}$ The evolution of each band with $p$ is discussed in relation with the $\mathrm{Si}-\mathrm{N}$, $\mathrm{Si}-\mathrm{H}$, and $\mathrm{N}-\mathrm{H}$ bond densities. The number of bonds is determined by integrating the different stretching absorption bands using the formula $A \int \alpha(\omega) / \omega \mathrm{d} \omega$, were $\omega, \alpha(\omega)$, and $A$ are the wave number, the absorption coefficient, and a calibration factor, respectively. $A$ is equal to 6.3 $\times 10^{18} \mathrm{~cm}^{-2}, 9.2 \times 10^{19} \mathrm{~cm}^{-2}, 2.8 \times 10^{20} \mathrm{~cm}^{-2}$ for the $\mathrm{Si}-\mathrm{N}$, $\mathrm{Si}-\mathrm{H}$, and $\mathrm{N}-\mathrm{H}$ stretching bands, respectively. ${ }^{17}$ The bond densities (Fig. 3) were obtained by dividing the number of bonds by the film thickness which was determined by fitting the UV-Vis-NIR transmission spectra. ${ }^{21}$ As $p$ increases, the number of $\mathrm{Si}-\mathrm{H}$ bonds decreases and is equal to zero for the sample prepared with $p=100 \%$. In the same time, the $\mathrm{Si}-\mathrm{H}$ stretching band shifts towards higher wave numbers indicating that an increasing number of nitrogen atoms are back bonded to the silicon one. For increasing $p$ values, the number of $\mathrm{N}-\mathrm{H}$ bonds increases with a maximum obtained for $p=50 \%$, and then decreases to zero. The Si-N bonds number continuously increases with $p$.

The PL spectra of the $a-\mathrm{SiN}_{x}: \mathrm{H}$ films are compared in Fig. 4. The film with $p=8 \%$ exhibits the PL phenomenon with an energy at the maximum $E_{\mathrm{PL}}=1.65 \mathrm{eV}$. As more nitrogen is incorporated in the film, the PL intensity increases rapidly with a maximum for the sample prepared with $p$ $=50 \%$. There is an improvement of the PL intensities with a shift of $E_{\mathrm{PL}}$ up to $1.78 \mathrm{eV}$. For $p=60 \%$, the PL intensity decreases and the PL energy remains equal to $1.78 \mathrm{eV}$. For $p$ greater than $60 \%$, the PL disappears.

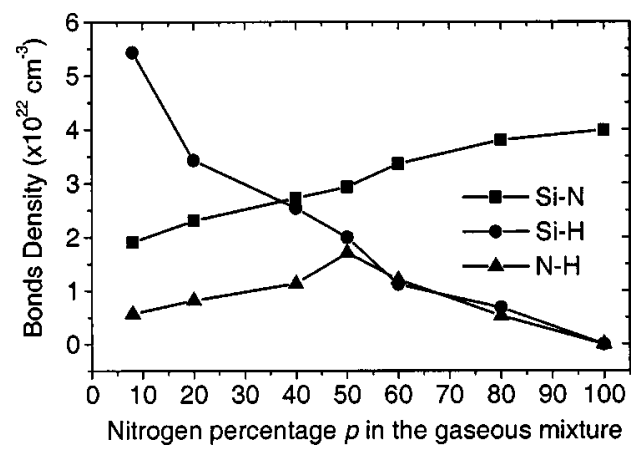

FIG. 3. Densities of $\mathrm{Si}-\mathrm{H}, \mathrm{Si}-\mathrm{N}$, and $\mathrm{N}-\mathrm{H}$ bonds as a function of the

nitrogen percentage $p$ in the gaseous mixture are shown. investigations, it can be assumed that the PL phenomenon is
Downloaded 25 Jan 2002 to 194.254 .100 .10 . Redistribution subject to AlP license or copyright, see http://ojps.aip.org/aplo/aplcr.jsp

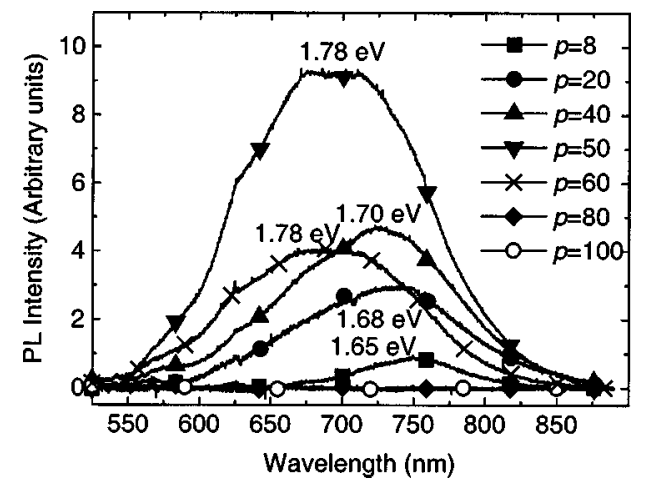

FIG. 4. PL spectra of the $a-\mathrm{SiN}_{x}: \mathrm{H}$ samples prepared with the different $p$ values are shown. (The numbers indicate the energy corresponding to the PL peak maximum $\left.E_{\mathrm{PL}}\right)$.

The different stages of the PL evolution could be explained thanks to the infrared absorption and optical gap measurements. The infrared mode at $630 \mathrm{~cm}^{-1}$ indicates the presence of nitrogen-free hydrogenated-silicon region. Raman spectra (not shown here) also exhibit a strong band at $480 \mathrm{~cm}^{-1}$ which is characteristic of amorphous silicon. These results allow one to assume that the films contain amorphous hydrogenated-silicon domains embedded in a silicon nitride matrix. The silicon nitride optical gap is greater than the hydrogenated-silicon one which involves the carriers confinement in the silicon clusters and allows the PL to be observed in our films. For the film prepared with $p=8 \%$, the PL intensity is low and the Tauc gap equal to $1.96 \mathrm{eV}$. This low value suggests that the film contains a lot of silicon dangling bonds. Those dangling bonds probably act as nonradiative defects and limit the PL efficiency. Moreover, it can be thought that the size of the silicon domain is too large to present the confinement effect. For higher $p$ values up to $50 \%$, the Tauc gap increases. This improvement of the Tauc gap can be attributed both to the greater nitrogen concentration of the silicon nitride matrix and to the more efficient passivation of the silicon dangling bonds. Hence, the PL intensity continuously increases which is explained by a greater silicon-domain-number and by a decrease of the defects. A PL blueshift is also observed for increasing $p$. The number of $\mathrm{Si}-\mathrm{N}$ bonds is an increasing function of $p$ as seen in Fig. 3. The $\mathrm{Si}-\mathrm{N}$ regions become more extended and surround $a$-Si clusters which are more numerous but smaller. The blueshift in $E_{\mathrm{PL}}$ could be explained by the decrease of the silicon domain size. For $p>50 \%$, the PL intensity decreases and is equal to zero for $p$ higher than $60 \%$. This decrease is correlated to the Tauc gap diminution down to 1.4 $\mathrm{eV}$. This evolution of the PL intensity and of the Tauc gap energy can be attributed to the increasing number of dangling bonds induced by the low number of $\mathrm{Si}-\mathrm{H}$ bonds. There is not enough hydrogen in the mixture so as to passivate all the dangling bonds. For the unhydrogenated sample, the PL phenomenon does not exist in as-deposited film. However, it has been shown that annealing treatments improved the structure and diminished the nonradiative defects number which allows to obtain the PL phenomenon. ${ }^{15}$

As a conclusion, $a-\mathrm{SiN}_{x}: \mathrm{H}$ materials emitting visible light at room temperature and without any annealing treatment have been prepared. Thanks to structural and optical investigations, it can be assumed that the PL phenomenon is AlP license or copyright, see http://ojps.aip.org/aplo/aplcr.jsp 
due to the confinement of $a$-Si clusters in a silicon nitride matrix. The role of hydrogen is of prime importance because it enables to passivate the silicon dangling bonds and to limit the nonradiative defects number.

${ }^{1}$ H. Morisaki, H. Hashimoto, F. W. Ping, H. Nozawa, and H. Ono, J. Appl. Phys. 74, 2977 (1993).

${ }^{2}$ S. M. Prokes and O. J. Glembocki, Phys. Rev. B 49, 2238 (1994).

${ }^{3}$ M. S. Brandt, H. D. Fuchs, M. Stutzmann, J. Weber, and M. Cardona, Solid State Commun. 81, 302 (1992).

${ }^{4}$ R. P. Vasquez, R. W. Fathauer, T. George, A. Ksendzow, and T. L. Lin, Appl. Phys. Lett. 60, 1004 (1992).

${ }^{5}$ L. T. Canham, Appl. Phys. Lett. 57, 1046 (1990).

${ }^{6}$ H. Rinnert, M. Vergnat, G. Marchal, and A. Burneau, Appl. Phys. Lett. 72, 3157 (1998).

${ }^{7}$ F. Iacona, G. Frayo, and C. Spinella, J. Appl. Phys. 87, 1295 (2000).

${ }^{8}$ D. J. Lockwood, Z. H. Lu, and J. M. Baribeau, Phys. Rev. Lett. 76, 539 (1996).

${ }^{9}$ M. B. Yu, Rusli, S. F. Yoon, S. J. Xu, K. Chew, J. Cui, J. Ahn, and Q. Zhang, Thin Solid Films 377, 177 (2000).
${ }^{10}$ R. Carius, K. Jahn, W. Siebert, and W. Fuhs, J. Lumin. 31, 354 (1984).

${ }^{11}$ W. A. Jackson, T. M. Searle, and I. G. Austin, J. Non-Cryst. Solids 77, 909 (1985).

${ }^{12}$ R. C. Fang, Y. Z. Song, M. Yang, and W. D. Jiang, J. Non-Cryst. Solids 77, 913 (1985).

${ }^{13}$ V. A. Gritsenko, K. S. Zhuravlev, A. D. Milov, H. Wong, R. W. M. Kwok, and J. B. Xu, Thin Solid Films 353, 20 (1999).

${ }^{14}$ A. Aydinli, A. Serpengüzel, and D. Vardar, Solid State Commun. 98, 273 (1996).

${ }^{15}$ M. Molinari, H. Rinnert, and M. Vergnat, Appl. Phys. Lett. 77, 3499 (2000).

${ }^{16}$ J. Tauc, in Optical Properties of Solids, edited by F. Abeles (NorthHolland, Amsterdam, 1972), p. 303.

${ }^{17}$ S. Hasegawa, L. He, Y. Amano, and T. Inokuma, Phys. Rev. B 48, 5315 (1993).

${ }^{18}$ D. V. Tsu, G. Lucovsky, and N. J. Mantini, Phys. Rev. B 33, 7069 (1986).

${ }^{19}$ E. Bustarret, M. Bensouda, M. C. Habrard, J. C. Bruyere, S. Paulin, and S. C. Gujrathi, Phys. Rev. B 38, 8171 (1988).

${ }^{20}$ F. Giorgis, F. Giuliani, C. F. Pirri, E. Tresso, C. Summonte, R. Rizzoli, R. Galloni, A. Desalvo, and P. Rava, Philos. Mag. B 77, 925 (1998).

${ }^{21}$ R. Swanepoel, J. Phys. E 16, 1214 (1983). 